\title{
ALGUMAS REFLEXÕES SOBRE A LÓGICA EUROCÊNTRICA DA CIÊNCIA GEOGRÁFICA E SUA SUBVERSÃO COM A EMERGÊNCIA DE SABERES NÃO HEGEMÔNICOS
}

\author{
SOME REFLECTIONS ON THE EUROCENTRIC LOGIC OF THE \\ GEOGRAPHIC SCIENCE AND ITS SUBVERSION WITH THE EMERGENCE \\ OF THE NON-HEGEMONIC KNOWLEDGES
}

Joseli Maria Silva

Doutora - GETE - UEPG

joselisilva@uol.com.br Alides Baptista Chimin Junior Mestrando - GETE - UEPG alides.territoriolivre@gmail.com Almir Nabozny Mestre - GETE - UEPG almirnabozny@yahoo.com.br Marcio Jose Ornat Mestre - GETE - UEPG geogenero@gmail.com Rodrigo Rossi Mestrando - GETE - UEPG iri.rodrigo@uol.com.br

\section{Resumo}

Este artigo é fruto de reflexões realizadas sobre nossa trajetória de pesquisa no Grupo de Estudos Territoriais da Universidade Estadual de Ponta Grossa desde o ano de 2003, envolvendo trabalhos relacionados às temáticas de "espaço e gênero, sexualidades e identidades". Nossa formação como pesquisadores que compartilham angústias e questionamentos de nosso papel na construção da ciência geográfica é aqui compartilhada. Como temos elegido grupos e temáticas pouco exploradas pela comunidade geográfica brasileira, estabelecemos duas questões que norteiam nossa exposição: 1) Quais os fundamentos da ciência geográfica brasileira, capazes de produzir invisibilidades e ausências de determinados grupos humanos? 2) Qual é o 
papel do pesquisador, que opera com os conceitos e métodos da ciência geográfica, na produção da visibilidade dos seres ocultados pelo padrão científico hegemônico instituído? Para tanto, realizamos uma discussão em torno do padrão eurocêntrico que marcou a geografia moderna e que influenciou a produção geográfica brasileira e, posteriormente, compartilhamos nossas opções teórico-metodológicas que nos possibilitaram construir uma geografia subversiva e plural.

Palavras-chave: Geografia; Epistemologia Feminista; Metodologias.

\begin{abstract}
This article is the result of reflections carried along our trajectory of research at Territorial Study Group/ State University of Ponta Grossa since 2003, involving studies related to the theme "space and gender, sexualities and identities". Our formation as researchers who divide distresses and inquiries of our role in the construction of Geographic Science is shared here. As we have chosen groups and issues that are less explored by Brazilian geographic community, we have established two topics that has guided our presentation. 1) What are the bases of Brazilian Geographic Science, capable of producing invisibilities and absences of some determined human groups? 2) What is the role of the researcher, who works with the concepts and methods of Geographic Science, in the production of the visibility of the human beings hidden by the established hegemonic scientific standard? Thus, we have carried out a debate on the Eurocentric standard that has characterized the modern Geography and has influenced the Brazilian geographic production. Later on, we have shared our theoretical-methodological options which have made possible to construct a subversive and plural Geography.
\end{abstract}

Keywords: Geography; Feminist Epistemology; Methodologies.

\title{
Introdução
}

Este trabalho é fruto de reflexões elaboradas no Grupo de Estudos Territoriais (GETE) da Universidade Estadual de Ponta Grossa - PR que, desde o ano de 2003, vem desenvolvendo pesquisas e trabalhos de extensão que envolvem a relação entre espaço e gênero, sexualidades e identidades. Nossa trajetória teórica e metodológica tem sido objeto de discussões internas e de sistematizações que devem ser compartilhadas com a comunidade geográfica.

Para debater com nossos colegas, trazemos duas questões 
fundamentais que inquietam o GETE e em certa medida, inspira nossa caminhada como pesquisadores. Quais os fundamentos da ciência geográfica brasileira, capazes de produzir invisibilidades e ausências de determinados grupos humanos? Qual é o papel do pesquisador, que opera com os conceitos e métodos da ciência geográfica, na produção da visibilidade dos seres ocultados pelo padrão científico hegemônico? As questões estabelecidas são o fio condutor do texto que segue e que propomos para o debate.

\section{A Invenção do Conhecimento Geográfico Moderno e a Ocultação do Saber Colonial}

A história da ciência não consiste em fatos, mas de interpretações dos fatos, argumentava Feyeraband em 1975 Para o autor, os fatos não existem em si, são frutos das idéias produzidas por pessoas posicionadas em determinados ângulos de visão e interpretação da realidade social. $O$ conhecimento científico, assim compreendido, é produto humano, socialmente produzido e não há neutralidade na sua produção. Pelo contrário, ele resulta de relações complexas de poder em tempos e espaços determinados, como afirmado por Morin (1996-a).

A emergência da ciência enquanto saber hegemônico se dá na efervescência cultural, econômica, política e social do Ocidente Europeu dos séculos XVI e XVII. Este conhecimento socialmente constituído se associou à técnica e passou a fazer parte das instituições educacionais, empresas, Estado e também na vida social cotidiana. Por sua vez, "os efeitos da ciência não são simples nem para o melhor, nem para o pior. Eles são profundamente ambivalentes. Assim, a ciência é, intrínseca, histórica, sociológica e eticamente, complexa" (MORIN, 1996-a, p.09).

A idéia de ciência moderna, iniciada no século XVI se estende posteriormente ao século XVIII como saber supremo oriundo do ocidente branco, masculino, heterossexual e triunfa sobre os "outros", considerados incapazes da faculdade de produzir conhecimento(s), como por exemplo, os 
incas, árabes, indianos, chineses, tupis-guaranis e assim por diante.

A modernidade é par complementar da colonialidade, elas se constroem mutuamente. Mignolo (2004) argumenta que a história do saber foi construída pela visão eurocêntrica e que o conhecimento do mundo colonizado foi silenciado pois, a

a colonialidade, permaneceu invisível sob a idéia de que o "colonialismo" seria um passo necessário em direcção à modernidade e à civilização; e continua a ser invisível hoje, sob a idéia de que o colonialismo acabou e de que a modernidade é tudo o que existe. Uma das razões para só se ver a metade da história é que esta foi sempre contada do ponto de vista da modernidade. A colonialidade era o espaço sem voz (sem ciência, sem pensamento, sem filosofia) que a modernidade tinha, e ainda tem, de conquistar, de superar, de dominar. (MIGNOLO,2004, p.666)

A Geografia é um tipo de conhecimento científico da era moderna/colonial. Fruto dos interesses ocidentais/europeus, brancos do sexo masculino. Lembremos os personagens, considerados precursores da Geografia Moderna: Alexander von Humboldt e Carl Ritter, inspirados no positivismo de Kant e no romantismo de Herder.

Alexander von Humboldt nasceu em 1769 em Berlim no seio de uma família aristocrática prussiana. Em 1789 iniciou seus estudos universitários e tornou-se um dos mais importantes naturalistas do século XIX, produzindo conhecimentos nas áreas de Biologia, Geologia e Geografia.

Devido sua tradição aristocrática, Humboldt conseguiu permissão da Espanha para explorar as Américas, na época, colônias espanholas. Em 1799 partiu da Espanha e um ano depois estava nas terras que se constituiriam a atual Venezuela. Sua exploração nas Américas durou cerca de cinco anos e resultou em trinta volumes de escritos sobre informações da área entre os anos 1805 e 1834. A obra de maior vulto de Humboldt é intitulada "O Cosmo", considerada como o mais importante trabalho científico já produzido. Para Humboldt a Terra era um todo indissociado e as partes eram interdependentes, incluindo o "homem" nesta relação. Ele acreditava que ao descrever as interações entre os fenômenos, através do método indutivo, poderia chegar às 
generalizações.

Carl Ritter nasceu em 1779 e segundo Capel (1982), era filho de uma família burguesa de poucas posses. Realizou seus estudos universitários com ajuda financeira e acabou tornando-se professor de Geografia, catedrático da universidade de Berlin fundada em 1810. Ritter foi um grande observador da natureza e também se pautou pela idéia da "unidade na diversidade". Ele apresenta algumas similaridades com as idéias de Humboldt, como a noção da interconexão dos fenômenos e a utilização do método indutivo através de constantes observações, até produzir as generalizações. Contudo, diferentemente de Humboldt, Carl Ritter era claramente um geógrafo preocupado com o homem na sua relação com a natureza. Sua perspectiva de unidade de área e diferenciação influenciará, mais tarde, Richard Hartshorne nos Estados Unidos. Importante destacar a diferença entre Humboldt e Ritter no que diz respeito às raízes filosóficas. Ritter acreditava na unidade da Terra como Humboldt. Entretanto, ele concebia que a natureza e sua organização possuíam uma finalidade específica traçada por Deus. Sua obra mais importante foi "Erdkunde" que se tratava de uma comparação de grandes regiões do planeta. A África e a Ásia foram seus referenciais mais importantes. Sua obra foi publicada em dezenove volumes entre 1817 e 1859.

Mesmo guardando as diferenças entre as idéias destes pensadores, há convergências de ações no que diz respeito à colonização empreendida pela Europa e sua superioridade sobre os povos habitantes das áreas tropicais e do "novo mundo". Capel (1982) transcreve um trecho de Humboldt a partir de sua obra Relación histórica del Viaje de las Regiones equinocciales realizada entre 1799 e 1804:

bajo un clima suave y uniforme, la única necesidad urgente del hombre es la alimentación. Es el sentimiento de esta necesidad el que excita para el trabajo; y se comprende fácilmente porqué, em medio de la abundancia, a la sombra de los bananos y del árbol del pan, las facultades intelectuales se desarrollen más lentamente que bajo un cielo riguroso, em la región de los cereales, em donde nuestra especie está constantemente em lucha com los elementos. (HUMBOLDT apud CAPEL, 1982, p.26) 
Este trecho evidencia o olhar eurocêntrico sobre o saber dos outros povos que possuem suas "faculdades intelectuais" menos desenvolvidas. Capel (1982) transcreve os argumentos de Carl Ritter sobre as razões de um "destino" inquestionável da superioridade da Europa em relação à outros continentes e povos, ainda no século XIX:

\begin{abstract}
El más pequeño de los continentes [a Europa] estava, así, destinado a dominar a los más grandes (...) Si se sabe que la vocación se há encontrado confirmada a nivel de la historia universal, se sabe menos que eso estaba de alguna forma inscrito em ella desde toda la eternidad; se atribuye el honor por ello al hombre europeo, mientras que éste no le corresponde más que em partes (...) Europa estaba, efectivamente, destinada a convertirse em el crisol de las riquezas y las tradiciones del Viejo Mundo al mismo tiempo que un lugar privilegiado para el desarrollo de la actividad intelectual y espiritual propria para absorber y organizar el conjunto de la humanidad. (RITTER apud CAPEL, 1982, p. 59-60)
\end{abstract}

Sem desmerecer a contribuição destes intelectuais na construção da ciência geográfica, o que se quer evidenciar aqui é que houve a disseminação de um saber eurocêntrico, um sentido único de abordagem dos chamados 'Pais da Geografia', pautados pelos valores e pela hegemonia dos povos ditos modernos, os colonizadores e civilizadores da humanidade.

Ao estudarmos a história do pensamento geográfico, é preciso deixar claro, estamos absorvendo o discurso da ciência moderna, produzida por homens brancos, europeus e ocidentais. Assim, não é de estranhar que os conteúdos, métodos e personagens da história do pensamento geográfico expressem a versão do poder hegemônico.

O Brasil e a América Latina são frutos do colonialismo português e espanhol e isso marca profundamente os traços de nossa sociedade. Não podemos negar o aprendizado. A Geografia brasileira é também a legitimadora das "frentes colonizadoras" dentro do próprio território brasileiro como argumenta o geógrafo Antônio Carlos Robert de. Moraes $(1991 ; 1994)$.

A primeira instituição oficial da prática do conhecimento geográfico brasileiro foi o Instituto Histórico e Geográfico Brasileiro, fundado no Rio de Janeiro em 1838 a fim de construir um acervo documental e de registros sobre 
a História e a Geografia brasileira. Um dos maiores apoiadores e o patrono da instituição foi D. Pedro II e na lista de sócios-fundadores da instituição estão pessoas da elite econômica, militar e jurídica da época. Interessante é destacar o forte vínculo da Geografia à força militar, pois o primeiro diretor da área de Geografia foi o Marechal Raimundo José da Cunha Matos, ligado à força militar ${ }^{1 .}$.

A prática de conhecimentos geográficos se institucionalizou como disciplina acadêmica no Brasil na década de 30 do século XX. Durante esta década surgiram várias instituições que fundamentaram a disciplina no país. Moraes (1991) enumera a criação dos cursos universitários em São Paulo e no Rio de Janeiro quase que simultaneamente em 1934 e a fundação da Associação dos Geógrafos Brasileiros (AGB). A criação do Conselho Nacional de Geografia em 1937 e o Instituto Brasileiro de Geografia e Estatística (IBGE) em 1939. A ata de fundação da AGB registrada em 17 de setembro 1934 consta os personagens de nossa história científica. ${ }^{2}$

Uma Geografia genuinamente brasileira é impossível de ser concebida, simplesmente porque o Brasil nasce com o aprofundamento da modernidade e a ciência por nós praticada é fruto da visão eurocêntrica do conhecimento, com seus vícios ou ilusões. Não podemos negar nossas raízes coloniais. A ciência geográfica é uma ciência moderna e, portanto, fundada nos pressupostos da razão, da objetividade e da neutralidade, produzida como verdade por homens brancos, europeus heterossexuais e cristãos. É este modelo de saber universal, consagrado como superior, que suplantou outros tipos de conhecimentos, considerados inferiores, como o conhecimento dos indígenas, dos negros, das mulheres, por exemplo. Se compreendermos a ciência como um discurso que deve ser debatido e não cultuado, que seu status superior deve ser questionado e não naturalizado, poderemos avançar em direção à um "conhecimento prudente para uma vida decente" como propõe Boaventura Santos (2004).

Lander (2005) nos lembra também que a modernidade só existe em função da colonialidade. São faces complementares e contraditórias que se alimentam mutuamente. É a subjetividade colonial presente na sociedade 
brasileira que faz com que os brasileiros "brancos" sintam-se superiores aos brasileiros "negros" ou "índios", por exemplo. Ou ainda, que as civilizadas populações das áreas urbanas ou ricas devam "levar" o progresso aos sertanejos, atrasados ou aos indígenas primitivos e assim por diante.

É claro que a Geografia produziu e ainda produz muito "sobre" o Brasil. Atualmente, é comum a produção geográfica "sobre" os índios, "sobre" as populações ditas tradicionais. Contudo, o lugar da enunciação do discurso científico é ainda eurocêntrico. Produzir sobre eles não é a mesma coisa que respeitar a expressão de suas próprias formas de conhecimento(s). Ao produzir sobre eles, do alto do altar científico, simultaneamente estamos também produzindo uma versão de suas imagens que, em geral, é hegemônica. É preciso ter consciência disso. Nesse sentido, é necessário admitir que não há uma Geografia "puramente" brasileira.

Há de se reconhecer nossa história científica, sem, no entanto, perder de vista a necessária crítica ao modelo instituído. Não se pode negar que praticamos a Geografia eurocêntrica como geógrafos brasileiros. Criticar o eurocentrismo não é, portanto, adotar uma postura auto-centrada, ignorando a produção científica estrangeira, mas produzir o saber de forma dialógica onde todos os grupos possam construir as versões plurais da realidade social. Descolonizar o conhecimento geográfico brasileiro não significa negar nossa história, mas produzir um conhecimento do ponto de vista da colonialidade e não da modernidade. Este é um grande desafio a ser enfrentado.

Se a ciência é parte da modernidade, para produzir um conhecimento geográfico do ponto de vista da colonialidade é preciso inventar outra forma de conhecimento, fora do campo científico? Edgar Morin (1996-b) nos diz que não. Argumenta que devemos trabalhar "com" e "contra" os conceitos. Isso é, procurando desvendar a perspectiva de quem os formulou, sua visão de mundo e sua posição de poder. Mignolo (2004) traz a idéia de que se não podemos escapar completamente à ideologia da ciência moderna, é preciso não aceitar o monotopismo, pensar através das fissuras dos quadros conceituais e ter a consciência da geopolítica do conhecimento estruturadas na diferença colonial epistêmica.

ISSN 1981-9021 - Geo UERJ - Ano 11, v.2, n.19, $1^{\circ}$ semestre de 2009.p.1-16. www.geoueri.ueri.br/ojs 


\title{
A Geografia Nossa de Cada Dia: Produzindo Com e Contra a Geografia Hegemônica
}

A questão sobre o que venha a ser a ciência, segundo Morin (1996-a), é uma pergunta que nós cientistas não temos a prática de perseguir. Segundo ele, a separação entre o sujeito e o objeto da ciência fragiliza e limita a atitude reflexiva do pesquisador em torno do "conhecimento do conhecimento".

\begin{abstract}
o método científico se baseou na disjunção do sujeito do objeto, e o sujeito fora remetido a filosofia e a moral.(...) Assim, ninguém está mais desarmado do que o cientista para pensar sua ciência. A questão 'o que é a ciência?' é única que ainda não tem nenhuma resposta científica. É por isso, mais do que nunca, se impõe a necessidade de auto-conhecimento do conhecimento científico, que deve fazer parte de toda política da ciência, como da disciplina mental do cientista. O pensamento de Adorno e Habermas recorda-nos incessantemente que a enorme massa do saber quantificável e tecnicamente utilizável não passa de veneno se for privado da força libertadora de reflexão. (MORIN, 1996-a, p.21)
\end{abstract}

A Geografia é, portanto, o que nós geógrafos fazemos dela. Nesse sentido, a prática da pesquisa deve estar submetida à uma constante crítica. Construímos a Geografia cotidianamente através das investigações concretas que realizamos fruto das escolhas teórico - metodológicas que efetuamos e validamos junto à comunidade científica, conforme o consenso sócio-cultural e histórico eleito por ela. A compreensão construtivista da ciência aqui adotada é importante para compreender que a versão hegemônica difundida pela história do pensamento geográfico é fruto de fortes relações de poder, conforme argumenta Corrêa (2006).

É a concepção de ciência como um saber socialmente construído que nos possibilitou questionar as ausências e silêncios do discurso geográfico e a afirmar, tal qual Mignolo (2004), que a Geografia científica hegemônica está profundamente marcada por privilégios de sexo e raça. É certo que estas 
críticas já foram realizadas por geógrafas feministas anglo-saxãs desde os anos 70 do século passado, conforme pode ser visto no trabalho de Oberhauser et all (2003). Contudo, a Geografia brasileira permaneceu impermeável ao processo de abertura às vertentes feministas e raciais. Podese dizer que é nos anos 90 com a ascendência da Nova Geografia Cultural no Brasil que as perspectivas de gênero, sexualidade e de raça passaram a fazer parte, ainda que de forma esporádica, das agendas de pesquisa nacionais.

Assim, mesmo que a Geografia científica hegemônica seja marcada pela perspectiva científica branca, masculina e ocidental, ela não é universal e novas perspectivas podem ser construídas. Como profissional do campo da Geografia, não é difícil observar a pequena abordagem de determinados agentes produtores do espaço como os negros, as mulheres, as crianças, os homossexuais etc. É com base na possibilidade de construir a versão dos grupos silenciados no discurso geográfico que temos trabalhado e criado caminhos teóricos e metodológicos que contemplem as versões plurais da realidade.

A produção científica que visa enfocar justamente o campo colocado à margem pela ciência hegemônica é complexa porque exige do pesquisador que ele opere com conceitos do campo científico eleito e compreenda como sua construção produziu os silêncios que se quer enfocar. Assim, é quase como produzir um discurso científico pelo avesso. Refletir o processo de pesquisa e a posição do sujeito pesquisador é um trabalho que a geógrafa Rose (1997) realiza em Situating knowledges: positionality, reflexities and other tactics. A autora chama atenção para as perspectivas de posicionalidade e reflexibilidade do(a) pesquisador(a) em relação à produção do conhecimento e argumenta que no processo de pesquisa estamos implicados no fenômeno e o que obtemos são versões localizadas. A autora alerta para ao fato da produção do conhecimento geográfico, ou seja, aquilo que criamos através de nossas pesquisas, passa a fazer parte da realidade estudada, assim como a realidade faz parte do conhecimento científico.

Três caminhos de discussão em torno da prática de pesquisa do GETE $^{3}$ têm sido desenvolvidas. A primeira delas diz respeito ao acolhimento das 
referências teóricas internacionais, notadamente as inglesas e norteamericanas, em nossos estudos e a manutenção da crítica ao eurocentrismo.

Nós nos identificamos com a vertente feminista e dos estudos queer ${ }^{4}$ que inquestionavelmente se desenvolveram com maior intensidade nos países anglosaxões. Quando nos referimos à crítica ao eurocentrismo, não quer dizer que não devemos nos utilizar de abordagens teóricas ou metodológicas realizadas por colegas europeus. Pelo contrário, quando criticamos o Eurocentrismo, estamos nos referindo à uma referência histórica / geográfica da acumulação da riqueza material e da hegemonia de um modo de conceber a sociedade a partir de um determinado espaço/tempo que se colocou como universal, anulando as diferenças plurais da humanidade e instituindo as dualidades à partir de uma imagem ideal de si, como o melhor e único modelo linear a ser seguido pela humanidade.

De tal modo, podemos afirmar, por exemplo, que as elites da América Latina possuem uma visão eurocêntrica do mundo. Não é a denominação nacional ou territorial que define as identidades e posturas, mas a forma de conceber as relações humanas.

A segunda linha de discussão é a adoção das perspectivas feminista e queer num grupo de pesquisadores que, até o momento, é hegemonicamente masculino. Há muitos equívocos na compreensão da relação entre pesquisadores, pesquisados e escolhas teóricas.

Afirmamos que em nossa prática de pesquisa constatamos que não necessariamente é preciso ter um corpo ou uma identidade de gênero feminina para se identificar com um conhecimento libertador para as mulheres e utilizar a epistemologia feminista, por exemplo. Ou ainda, ser homossexual, transsexual para se utilizar da perspectiva queer. A epistemologia feminista não é, em hipótese alguma, um saber instituído de mulheres que não pode ser também praticado por homens. A referência ao feminino de tal proposta epistemológica ocorre pela alusão da origem do movimento contestatório da ciência que possibilitou formas diferentes de construir o saber científico para além do campo da ciência moderna, objetiva, neutra e universal. Foram as 
geógrafas brancas, em sua maioria de universidade de países ricos que denunciaram os "privilégios" epistêmicos e a hegemonia masculina, contudo não universal como pretendia ser. Segundo Mignolo (2004, p. 685)

as epistemologias feministas contribuíram de maneira impressionante para descentrar e memorizar os pressupostos patriarcais da ciência ocidental e da revolução científica e das duas conseqüências históricas, políticas, epistêmicas e éticas

A adoção das perspectivas geopolíticas e feministas do conhecimento não deve levar à uma associação direta entre nacionalidades ou a percepção imediata de corpos que praticam o conhecimento. Por exemplo, uma mulher pode defender e enquadrar-se perfeitamente no modo de produzir o conhecimento moderno, pautado pelo saber masculino. Da mesma forma podemos encontrar homens praticando a epistemologia feminista e pessoas que nasceram na Europa incorporando um discurso descolonizador do conhecimento. O importante é marcar a idéia de que o que está em jogo são as formas de projetar a vida, a ética e a política. Assim, não há uma linearidade natural entre o ser que age e as características representacionais à ele atribuídas.

A terceira linha de discussão é a implicação daquilo que produzimos como ciência na construção da realidade estudada e nosso compromisso com a promoção dos grupos sociais que investigamos. Nesse sentido, é preciso deixar claro que, embora tenhamos a consciência de que estamos optando pela pesquisa de pessoas que estão à margem de muitos benefícios sociais, lutamos por não reforçar as tradicionais imagens de vítimas passivas tão comuns nas abordagens das mulheres, crianças, negros, índios e homossexuais.

Pelo contrário, nossas opções metodológicas têm sido produzidas para exaltar as suas potencialidades, táticas de vivência, saberes específicos que os possibilitam viver, apesar de suas condições sociais e econômicas desfavoráveis. Esta postura tem sido objeto de auto-crítica das práticas de pesquisas desenvolvidas no grupo. Sendo mais objetivos, realizamos um 
exercício de discussão acerca daquilo que produzimos, no sentido de abolir a supremacia daquilo que nós interpretamos das práticas dos grupos estudados e temos estimulado a versão daquilo que os próprios grupos pensam sobre suas práticas e a realidade social que vivem e constroem.

Enfim, as experiências e ensaios que temos desenvolvido no GETE foram aqui compartilhadas, no sentido de construir um diálogo metodológico com os demais grupos de geógrafos preocupados com o desenvolvimento de um espírito crítico, questionador das verdades absolutas e inovador, negando a monótona repetição de conceitos e teorias.

\section{Considerações Finais}

Nossos argumentos bradam para que a Geografia seja compreendida como fruto das escolhas que nós geógrafos fazemos. Temos opções de, mesmo adotando ferramentas teóricas já produzidas, desconstruir o discurso colocado 'sobre' nós brasileiros, 'sobre' os indígenas, mulheres ou negros. É preciso lutar pela emergência do conhecimento geográfico brasileiro, reconhecendo nossas raízes coloniais com base na crítica à naturalização das verdades geográficas e abrindo caminhos alternativos para as versões plurais do conhecimento e possibilitar a enunciação do ponto de vista dos silenciados.

\section{Notas}

1 - http://www.ihgb.org.br/ihgb.php, Acesso em 20/02/2008.

2- http://www.agb.org.br. Acesso em 21/02/2008.

3- Maiores detalhes acessar o sítio da Rede de Pesquisadores de Geografia e Gênero da América Latina (REGGAL).In: http://www.reggal.uepg.br/modules/wfdownloads/

4- O pensamento acadêmico queer foi desenvolvido a partir de uma contestação ao movimento social homossexual norte-americano de caráter 
conservador que privilegiava a representação do homem branco, homossexual, de classe média alta e excluía a diversidade presente no movimento de luta pela liberdade sexual, também composto por não brancos, travestis, lésbicas e transexuais, etc. Os pensadores queer comungam as idéias que a heteronormatividade e as hierarquias sexuais precisam ser questionadas, a fim de que outras realidades sejam visíveis, e também, que não há linearidade entre sexo, gênero e desejo, pois as identidades instituídas de ilimitadas configurações entre estes elementos estão em permanente transformação e sempre abertas ao novo.

\section{Referências}

AGB - Associação dos Geógrafos Brasileiros. Disponível in: http://www.agb.org.br/. Acesso em 21/02/2008.

CAPEL, Horacio. Filosofía y Ciencia en la Geografía Contemporánea. Barcelona: Barcanova, 1982.

CORRÊA, Roberto Lobato. Produção geográfica, controle e poder. Biblio 3W, Revista Bibliográfica de Geografía y Ciencias Sociales, Universidad de Barcelona, Vol. XI, $\mathrm{n}^{\circ} 650,5$ de maio de 2006. Disponível in: http://www.ub.es/geocrit/b3w-650.htm (ISSN 1138-9796). Acesso em 16/02/2009.

FEYERABEND, Paul. Contra o Método. Rio de Janeiro: Livraria Francisco Alves Editora S.A. 1977.

IHGB - Instituto Histórico e Geográfico Brasileiro. Disponível in: http://www.ihgb.org.br/ihgb6.php. Acesso em 20/02/2008. 
LANDER, Edgardo. Ciências sociais, saberes coloniais e eurocêntricos. In: LANDER, Edgardo (org). A colonialidade do saber. Eurocentrismo e ciências sociais. Perspectivas latino-americanas. Buenos Aires: CLASCO, 2005. p.21- 54

MIGNOLO, Walter D. Os esplendores e as misérias da "ciência": colonialidade, geopolítica do conhecimento e pluri-versalidade epistémica. In: SANTOS, Boaventura de Sousa (org). Conhecimento prudente para uma vida decente. São Paulo: Cortez, 2004. p.667-710.

MORAES, Antonio Carlos Robert. Notas sobre identidade nacional e institucionalização da geografia no Brasil. Estudos históricos. Rio de Janeiro, vol. 4 n. 8, p.166 -176, 1991.

Departamento de geografia: linhas de pesquisa. Estudos avançados. vol. 8, n. 22, p.359-364, 1994.

MORIN, Edgar. Ciência com Consciência. Rio de Janeiro: Bertrand Brasil, 1996-a.

O problema epistemológico da complexidade. Lisboa (Portugal): Europa - América, 1996-b.

OBERHAUSER, Ann M.; RUBINOFF, Donna; BRES, Karen De; MAINS, Susan and POPE, Cindy. Geographic perspectives on women. In: Gary L. Gaile and Crt. J. Willmott (Orgs). Geography in America at the down of the $21^{\text {st }}$ century. Oxford: Oxford University Press, 2003. p.736-758. 
ROSE, Gillian. Situating knowledges: positionality, reflexities and other tactics. In: Progress in Human Geography, v. 2.p.305-320, 1997.

SANTOS, Boaventura de Sousa (org). Conhecimento prudente para uma vida decente. São Paulo: Cortez, 2004.

Artigo encaminhado para publicação em junho de 2009.

Artigo aceito para publicação em agosto de 2009. 